\title{
Beyond rational choice: How teacher engagement with technology is mediated by culture and emotions
}

\author{
Carlo Perrotta ${ }^{1}$
}

Published online: 23 December 2015

C The Author(s) 2015. This article is published with open access at Springerlink.com

\begin{abstract}
This paper focuses on the relationship between rational beliefs, culture and agency in formal school settings. This relationship is analysed in the context of the adoption of technological innovations. Interviews and focus groups with 39 secondary teachers from England and other European countries were carried out. The analysis highlights a number of cultural differences between English teachers and their continental colleagues. The paper argues against a linear and simplistic appropriation of rational choice theory in educational research, whereby individual behaviour is examined from the perspective of individualist psychology and micro-economic theory without considering models of culturally informed agency beyond self-interest and calculation. In the conclusion, the paper argues that explanations of teacher agency in relation to technology must take into account the role of rationality and emotionality not as a binary opposition that reflects actual psychological qualities that teachers may or may not possess, but as phenomena to be unpacked: competing (and culturally shaped) discursive strategies enacted to make sense of the world.
\end{abstract}

Keywords Rational choice-Technology adoption - Educational culture - Teacher agency

\section{Rational choice, technology and teacher agency}

The conundrum of teachers' uses and non uses of technology in formal school settings has been for many years an important topic in educational research. At the heart of this "problem" lies an unresolved theoretical tension between competing models of teacher agency. On the one hand, there is a rationalistic and instrumentalist view of teachers' actions, which is grounded in psychological and economic explanations of human behaviour; on the other hand, there is a more sociological or "socio-cultural" position

Carlo Perrotta

c.perrotta@leeds.ac.uk

1 School of Education, University of Leeds, Leeds LS2 9JT, UK 
which sees agency as shaped by contextual forces and cultural meanings. The overarching aim of this paper is to tease out this tension and articulate an empirically grounded discussion which will advance theoretical development. The primary focus is on the relationship between rationality, culture and agency; this relationship is analysed in the specific context of the adoption of innovations in formal school settings. The paper assumes that the interaction between teachers and technology constitutes a vantage point from which to observe the interplay of beliefs, emotions and cultural discourses that shape choices and behaviours.

Rational choice can be considered as a unified, universal view of human behaviour informed by individualist psychology and the economic logic of market transactions, whereby individuals are seen as "rational maximisers of interest and utility" (Green et al. 1994: 3). This view is deeply embedded in most models of technology adoption not only in education but more broadly. In fact, technology is often used as a shorthand for rationality and efficiency, as aptly illustrated in the highly influential "diffusions of innovations model" (Rogers 2003), where technology is defined as "a design for instrumental action that reduces the uncertainty in the cause-effect relationships involved in achieving a desired outcome" (ibid: 13). Zhao and Frank (2003) conceptualise technology adoption in school settings along similar lines:

When teachers are given the opportunity and resources to experiment with computers, they may improve their technology proficiency and see how computers further their goals, that is, reduce perceived costs and increase perceived benefits (p. 817).

Strong rationalistic assumptions also underpin established models of individuallevel technology adoption, such as the Technology Adoption Model (TAM) (Davis 1989; Davis et al. 1989), which expands on the psychological theory of reasoned action (Fishbein and Ajzen 1975) and attempts to explain adoption patterns on the basis of quantifiable factors, chiefly the perceived usefulness of a certain technology and its ease of use. This model can predict quite accurately intentions to use and, to a degree at least, actual use of technology in a variety of contexts (Legris et al. 2003) - not least among school teachers (Scherer et al. 2015; Teo 2009). Although it should be noted that "behavioural intention" does not always translate into "actual" use, especially when uses and non-uses are analysed in situ through systematic observation and ethnographic approaches (Selwyn 2010; Selwym and Grant 2009). The TAM model has evolved significantly over the last couple of decades, incorporating a range of moderating factors which were found to influence the adoption of innovations (Straub 2009; Straub et al. 1997; Venkatesh et al. 2003). Despite this, the mainstream view of technological integration still reflects a rather restrictive model of individual rationality, insofar as it assumes that a linear (or at least broadly predictable) relationship exists between the personal beliefs and benefit-maximising dispositions of teachers and their actions (Ertmer, and Ottenbreit-Leftwich 2010; Jimoyiannisa and Komisb 2007; Kim et al. 2013). In the early 2000s, the main challenge of technology integration was a matter of gradually progressing from low-level to high-level uses over a period of approximately 5-6 years. This was, for many, the time needed for teachers to accumulate enough expertise to change their belief systems in ways that were more compatible with meaningful and "student-centred" uses of technology (Ertmer 2005). The 
predictions of technological integration through a rational "slow revolution" have been largely disconfirmed as the traditional realities of schooling - the "deeply entrenched structures of the self-contained classroom, departments, time schedules, and teachers' disciplinary training" (Cuban et al. 2001: 83) - have proved incredibly resilient to the sustained attacks of technological innovation.

At the time of writing, in 2015, this is still largely the case in spite of a widespread consensus about the potential benefits of digital technology in the classroom. A more realistic assessment of the current state of technological adoption in schools is that sometimes changes in beliefs lead to changes in behaviour in a fairly linear and rational fashion, for instance through strategies that increase confidence and a positive approach to risk-taking (Howard and Gigliotti 2015). However, just as often they do not, and many have noted the inconsistencies between teachers' "rational" beliefs about technology or pedagogy and their actions (Calderhead 1996; Ertmer et al. 2001; Fang 1996). In addition, empirical research has suggested a "filtering" effect of emotions (particularly negative ones) on beliefs about teaching, learning and motivation (Mansfield and Volet 2010).

Across these debates, the influence of culture on individual-level beliefs and even emotions is often recognised as crucial, but it remains theoretically underdeveloped and limited to two areas:

a) The analysis of school-level values and group dynamics among teachers, such as the cultural "distance" between innovative, technology-based practices and the pre-existing practices (Roehrig et al. 2007; Somekh 2008; Zhao \& Frank 2003).

b) The study of "cultural dimensions" (Hofstede et al. 1997) (power-distance, uncertainty avoidance, masculinity and individualism, see also Nistor et al. 2014); a theory which has been criticised for oversimplifying cultural differences between countries (Signorini et al. 2009).

Conversely, established sociological views emphasise the relative qualities of cultures and the non-homogenous nature of modern societies; thus the empirical study of the production and negotiation of culture is prioritised over the quantitative measurement of "cultural dimensions" or values, viewed as reified and fixed entities (Du Gay et al. 2013; Hall 1997).

According to this more sociological and anthropological view, it is impossible to analyse culture without a concern for processes of signification. It follows that the tendency of mainstream technology adoption models to rely on structured questionnaires poses problems in terms of ecological validity, because it precludes insights into everyday practices and meaning making processes which can only be appreciated through the deployment of more qualitative methodologies.

This paper tries to advance this theoretical and methodological discussion further, arguing that our understanding of the culturally shaped, rational and less-than-rational actions of teachers in relation to technology is still incomplete. In particular, the paper aims to develop an analysis from a range of observations and empirical materials collected over the course of two large scale international projects. In both cases, the aim was to understand the conditions that can foster "innovative teaching and learning" in formal secondary education. 
The paper will suggest that culture, not much (or not only) at the "local" and intragroup level but at the macro level of "discourses" and ideologies (which are then reflected in national policies and institutional values), acts as an additional filter or mediating factor for individual choices and behaviours. In the next section, I will briefly describe these projects and I will then summarise the empirical background which underpins the research questions. The remainder of the paper will focus on an empirical study involving a total of 39 secondary teachers from England and other European countries.

\section{Empirical background and research questions}

Innovative Teaching and Learning (ITL) was a 2-year international project sponsored by Microsoft Partners in Learning that investigated the conditions leading to innovation in formal learning contexts (see Langworthy et al. 2010). The project started in 2010 and ended in 2012. Seven participating countries which arguably reflect different facets of global education in the 21st century were chosen: the USA, Senegal, Mexico, Finland, Russia, Australia and England. The data discussed here is from the English strand in which the author was involved as a researcher; alternative accounts highlighting the international scope of the project are also available (Shear and Moorthy 2010). For the purpose of this paper it is worth reporting at least one finding from the international study, which involved 159 secondary schools and 4,038 teachers (683 of whom were in England). The analysis suggested that "innovation" is still largely a teacher-level phenomenon, with significant variation across classrooms even within schools which had already been identified as being at the forefront of technology integration. Most of the variation in teaching practice lied therefore between teachers within a school, not between schools.

The second project considered here is Innovative Technologies for an Engaging Classroom (iTEC): a large scale, 4-year European intervention with significant political support and financial backing from the European Commission of approximately three million Euros. The project, which started in 2010 and ended in 2014, involved 26 partners including ministries of education, technology providers and research organisations (Lewin and McNicol 2014). The author was employed as researcher in one of several research organisations mainly tasked with running workshops with secondary school teachers from a range of European countries in order to explore meaningful uses of technology in the classroom.

During the course of both projects a great deal of quantitative and qualitative data was collected through surveys, workshops, interviews and classroom observations. Only a subset of these data is considered here.

The overall picture which emerged from both projects was one where a positive view of digital technology "in abstract" - mainly in terms of accessing unspecified knowledge and supporting "21st century skills" - went hand in hand with rather mundane uses of actual tools and devices such as electronic whiteboards, laptop computers and tablets; and with a general confusion or uncertainty about the ability of digital technology and social media to enhance students' understanding of subject matter. Two more specific findings from ITL are worth highlighting for the purpose of this paper: 
a. Rather than individual characteristics, the social milieu in which schools were immersed influenced the degree to which teachers recognised those "abstract" benefits of digital technology. A survey of 683 teachers found that whilst deep understanding of subject matter was all around the weakest of all benefits associated with digital technology use, teachers in more "challenging" circumstances and less "performing" schools were more likely to think that ICT can benefit student learning (Author, 2013).

b. An observable pattern whereby individual "innovative" teachers were willing to accept - for reasons that can only be described as "micro-political"- the inconveniences and increased workload associated with far from ideal "technologyenhanced" practices. For example, to enact forms of harmless resistance in an attempt to escape the drudgery of daily teaching with its repetitive routines and restrictions (Author, 2013).

These findings set the stage for the main research questions that underpin this paper. The research questions are as follows: can teachers' engagement with technology be explained as a non-binary entanglement of rational and non-rational factors? How is such entanglement patterned according to cultural norms and influences?

\section{Methods}

The data considered in this paper were collected over a period of 5 years and across two projects. The overall methodological framework is consistent with the tenets of grounded theory (Glaser and Strauss 1967), as the reflective approach of the author, who was involved as a researcher in both projects, ties together different forms of qualitative and observational data, enabling the emergence of a coherent interpretive picture. More specifically, the analysis and the ensuing discussion draw on interviews, workshops and focus groups conducted at different points in time:

- four individual in-depth interviews with English teachers in 2011;

- two consecutive focus groups involving a total of 14 English teachers in 2011;

- a workshop involving 15 teachers from six European countries (Hungary, Spain, Italy, Turkey, France and Austria) in 2012;

- Individual in-depth interviews in 2015 with a subset of six European teachers (two from Italy, one from Austria, one from Hungary, two from Spain) who attended the workshop in 2012, which provided an opportunity to look retrospectively at the past experiences as "innovators" in a more critical and selfreflective fashion.

In addition, the interpretation builds on research notes and observations captured in a fairly unstructured manner and then systematised for the purpose of this paper. All interviews were conducted in English face-to-face or via Skype, and recorded using digital voice recorders or VOIP (Voice Over Internet Protocol) recording software with the consent of the participants. Semi-structured interviews were used during the data collection sessions. Sample probing questions to initiate in-depth conversations include the following: 
a) Why do you use technology in your daily practice?

b) What are the factors that influence when and how you use digital technologies?

c) Why do you think is important to use digital technologies in the classroom?

d) Do you see yourself as an "innovative" teacher? What does being more or less innovative mean to you?

The actual analysis was mainly phenomenological in nature (Sokolowski 2000), that is, concerned with descriptions of phenomena which were then clustered in discrete categories through a process of open coding. This process continued until "theoretical saturation" and was then followed by more selective coding in terms of the initial categories. Interviews were individually transcribed. The software for qualitative analysis Nvivo was used to organise the data and facilitate the coding process.

At a broad level, the use of technology in these innovative projects still appeared to be mostly based on individual initiative, and the data confirmed the key role played by "technology champions": teachers who saw themselves as experts and often acted as "consultants" for other teachers. Often these were ICT teachers, but not always. In one school the technology champion was a RE (Religious Education) teacher, in another school a biology teacher. A more in-depth analysis highlighted interesting cultural differences in the ways English teachers and their fellow "continental" colleagues construed their actions as innovative professionals. Two themes, or interpretive "nodes", emerged:

1. English teachers as "self-interested" actors, more pragmatic and well-versed in the politics and the economics of educational technology and actively "playing the game" of innovation to pursue benefits which, however, were largely "non-educational" in nature.

2. innovation as a form of "emotional activism" enacted by teachers from other parts of Europe, who shared a genuine and emotional "faith" in the power of digital technology as a "force for good".

These themes will be explored in more detail in the next section. All quotations reported in the next section are verbatim. Longer quotes are attributed using fake names and reproduced as freestanding text.

\section{Results}

\subsection{English "realism"}

English innovative teachers demonstrated a sophisticated understanding of the socio-political constraints within which they were called to make decisions about technology. They were keenly aware of the tension between individual autonomy and external control, whilst sharing realistic concerns about the limits of innovation in the very accountability-driven English school system, in which teachers and students were described as allies in the pursuit of maximum benefits at a minimum cost: 
Michael: many (students and teachers) are resistant to change - cloud-based spreadsheet which can be edited by more people at once? They hate that because they are all skilled users of old Office 2007! (Students) want to pass the course, they don't want to innovate - they want to be told what they have to do, and they want to get it done. Teachers will seek ways to do it the most effective way they can, and still have a life.

Innovation was construed as an ill-defined collection of creative and "funky" practices at the margins of rational, mainstream education. Not necessarily something "taking the school forward by all conventional measures" or "helping students get the best results". Nonetheless a necessary "irritant in the system" which in some cases can help students "have a more memorable experience" despite requiring "lots of effort":

$J u d y$ : is it efficient? Probably not. Is it taking the school forward? Very hard to measure how it's taking the school forward, but over 20 years, in a healthy institution you'll have elements of that happening.

Sue: you need to keep asking yourself: "what for?" Is it (technology) a better way of doing things, or just an expensive way of doing something very simple? Is it a worthwhile activity or not - you need to keep asking yourself "what for?"

Teachers believed that their success was dependent on a set of external factors and criteria which were not always compatible with innovative practices:

Robert: my success is going to be judged by exam results - by parental choice what parent want, what children want isn't necessarily what I would describe as innovative practice. What I cannot do is be funky and interesting and let my results slip - I just don't have that freedom.

These constraints were never portrayed in an overly negative light, but always accepted with a realistic demeanour that bordered sometimes on resignation:

Mary: there is a huge amount of content that needs to be delivered and it limits what you can do in terms of innovation. There is a timeframe by which you need to deliver it by... but thinking about it... I am a biology teacher, and if my students want to go on to higher education, they will need that content!

And yet, they agreed that their time and dedication as innovators was going to eventually pay off, yielding benefits which were not strictly "educational", but about the school's image as an innovative, future-facing organisation connected to the world of aspirational high-tech business. Several English teachers were actively involved with the school leadership in mediating relationships with major technology companies; this was described as a sign that the school was successful and capable of establishing "links with businesses". These links were also seen as crucial for the procurement of expensive equipment and software licences, and for accessing networks of information and support: 
Robert: it's twofold, we tell businesses that they can come in and talk to students, show how technology works and explain what innovation means, but it works also the other way, so that we can take something from them (...) it's a bit of a two way process.

Such rational, utilitarian exchanges weren't always smooth and were often hampered by the inconsistent and costly demands of technological integration, not least the onerous acquisition of expensive equipment, the costs of maintenance and upgrade, and the challenges of installing such equipment in old buildings which were not "fit for purpose". Nonetheless, teachers showed an extensive familiarity with the vagaries of ICT procurement. Themes of procurement were in fact very common and often dominated discussions meant to focus on the educational value of technologies:

Mark: ICT is a black hole, with very short product cycles, the costs of licences and upgrades are also prohibitive (...) it's taken me a whole year to establish a relationship with Apple, they have waiting lists, they have their issues, we got ours, etc.

The economics of educational technology acted as a lens through which the whole endeavour of innovation was often viewed. Interestingly, the drying up of financial support in one school led to the relaxation of this utilitarian mindset - something reflected in a more personal, emotional even, language. The exhaustion of funds softened somewhat the relentlessness of purchasing and updating cycles and offered the opportunity to "try something different", thus "taking control" of the educational process in a time of crisis.

Sue: we had a formal innovation group led by (...) with the aim to share good practice and open up opportunities. The purpose of that group was also to be able to bid for money $-25 \mathrm{k}$ - which would be able to facilitate that innovation. That funding ended. Because obviously underpinning all of this is a budget (...) But if the money isn't there it comes back to your personality.

Themes of "being brave" and resilient emerged during the discussion:

Mark: you have to be brave and rely on some judgement that it may be successful. There may be some teething problems (but) you should never stop trying! You have to take control. You've got to be brave enough to let people accept the things you are introducing. Because of budget cuts which have affected the hardware, people aren't going around spending huge amounts of money. Obviously you need capital investment but that isn't always the answer.

According to teachers, this more "emotional" approach could work only if embedded in the existing context with all its stringent demands. Realistic beliefs were therefore upheld, as evidenced in the emphasis shown by interviewees on integrating technology without disrupting the flow of schooling with its non-negotiable elements such as assessment, a limited school day and so forth. A "structured and disciplined" 
alignment was always needed; something that betrayed a tension between personal agency and a desire to fit in an ordered framework, which on one occasion was compared to "train-coupling" - an interesting technological metaphor, itself ostensibly underpinned by a strong rationalistic belief:

Michael: yes, train coupling! If it's too loose the train will come off the tracks, if it's too tight the train can't get around corners. (...) it's very clear that we are given freedom insofar as we can demonstrate that we can improve standards.

\subsection{Continental "emotional agency"}

When asked about the reasons to be involved in an international project, most teachers from mainland Europe mentioned the "opportunity to meet European colleagues" and "travelling to other European countries". The importance of this "European" dimension will be discussed later. For these teachers, innovation and the championing of digital technologies in the classroom seemed underpinned by a generalised anxiety about impending social change. Digital technologies were recruited as indispensable resources in a collective endeavour to create progressive and equitable societies. What follows is an extract from an interview with an Austrian teacher:

Franz: (...) it is necessary because life is changing. The need for change is what drives (technological) innovation. We don't have engineers, we need a change of agenda and we need girls in science. This is what society demands and schools should respond.

Interviewer: is it about social change?

Franz: yes exactly! If you want to progress ... society is changing so fast that you have to bring in new stuff on your own... We are having lots of innovation in Austria. Many migrants and a lot of children don't speak German when they start school. You can use different helpful tools to respond to this... this social change. The role of parents is also changing. Problems are getting more and more complex and often the separation between school and family is no longer there. Strategies to support families are changing. Before families were clearly defined and now we are having lots of patchwork families. Then there are broader changes in society... Austria is turning into an open society.

Similar accounts were given by other teachers during separate interviews, again showing anxiety in relation to the challenges of multiculturalism - challenges which are simultaneously caused and solved by digital technologies and the "internet" in particular:

Giulia: we need to innovate because Europe is changing - it has already changed.

Schools need to face complexity and diversity. Our schools are becoming a 
wealth of diversity. This is not only a cultural matter, with all these migrant children coming in.

Xavier: things are changing and we have to react to it (...) The net, the internet is the main thing we need to adapt to. A revolution is going on and it's caused by the internet. We need to help kids develop digital competences. Our roles need to change. The school's role needs to change radically.

Throughout the accounts "digital innovation" acted like a cultural Rorschach test: an undefined entity upon which general fears and concerns were projected. This projection was realised in emotional terms, whilst digital technology was construed as a determining factor and, simultaneously, the solution to pressing social challenges without recourse to rational, evidence-based argumentation. Interwoven through the accounts was also a specific type of identity, presented as pioneering, passion-driven ("I fell in love with innovation", one interviewee observed) and often fighting against the odds. Here is an account from an Italian teacher:

Anna: in my school I pioneered the introduction of computers in teaching and learning - many years ago. When the school leaders moved on (one passed away) it all died in my school. I revitalised this thing, which however still struggles to take off (...) Much has to do with my personality. I have always tried to innovate. I am an old teacher, 4 years from retirement, throughout my career I tried to innovate and continuously reinvent myself, to change, to find new solutions, because I believe it's a teacher's duty (to do this). As a teacher you must create an education that responds to the needs of students who change as society changes.

The story of Romea from Hungary provides a good example of how emotional agency and technology can become entangled. The story needs to be seen in the context of the larger project (iTEC) considered here. As a project, iTEC struggled to produce actual technological resources and applications in spite of its original mandate, and resorted half-way through to focus on the whole gamut of "the Internet" and its endless, free supply of "affordances": openness, learning, collaboration, entrepreneurship, and knowledge. At the same time, "app" became a catch-all term referring to a broad set of free digital resources which could support "web 2.0 learning" in generic pedagogic scenarios. During the workshop in 2012, Romea showed frustration at the vague nature of the process, becoming increasingly irritated and expressing doubts as to her ability to carry out the tasks outlined in the scenarios. In the follow-up interview, Romea was made aware of this interpretation as part of an attempt at "member checking" (Guba 1981). Member checking occurs when interpretations are relayed to research participants to check for perceived accuracy and reactions, thus increasing the overall credibility of a qualitative inquiry. Upon solicitation, Romea recalled that episode as well as similar others during which she did not feel "in control", as the situational demands seemed to challenge her self-image as an open-minded innovator. During the interview, she admitted to blaming herself rather than the situation, which for all intents and purposes was rather confusing and hardly "rational": 
Romea: I wasn't always in control - It made me nervous I couldn't handle things because I thought I should be familiar with them. I have always been open to anything new and innovative - I have always been a person like that.

Her own ability to overcome such uncertainty was therefore construed as the main achievement of her own personal and emotional journey as an "innovator". A journey which she managed to complete successfully despite the missing or failing equipment and the need for great personal investment in terms of time and effort:

Romea: it was a lot of work outside teaching and it took a lot of my private time. It required a lot of effort. We didn't always have the equipment, if you remember we had the TeamUp software and other 2.0 applications which didn't work in many cases - a lot of learning! The IT teachers at my school didn't help either they didn't teach students how to use these tools. They didn't know there are tools like these which exist in practice.

Romea was very keen to emphasise that all these efforts never amounted to a "job" or a formal commitment. Rather, it was a personal endeavour driven by passion and interest despite the unverified benefits:

Romea: Let's not call it a job (...) it wasn't a job in the strictest sense. I was always very open to innovation - technology, as it is. I was very interested to develop myself. I was very personally interested. I was very keen to be involved in a European project (...) I knew very little about the whole thing but I said yes anyway, because I was very motivated (...) The best thing was that I enjoyed it very much. It was a great success when we finally managed to make it work - it made me really proud!

\section{Discussion and conclusion}

The interpretive picture that emerges from the interviews is one where pragmatic calculation, irrational beliefs (i.e., not evidence-based), societal hopes and identity projects are wrapped around vaguely defined notions of "innovation" and technological affordances. Across both projects and both groups of teachers, technology was never described in terms of efficiency and standardisation. For all teachers involved, irrespective of cultural differences, innovation referred instead to a specific brand of soft "techno-progressivism" that seemed to be altogether ambivalent, fuzzy and very malleable. The interviews, considered in their entirety, suggest an interesting intermingling of economic rationalism and "silicon valley" aspirational rhetoric: a particular brand of technology-fuelled emotional discourse that celebrates personalisation, empowerment, well-being, and where "the Internet" is reified as a single piece of miraculous "tech" (Hartley 2003). The main differences lied in the degrees of cultural allegiance to this rhetoric. English teachers were more aware of a contradiction between what counts as "effective" in an accountability-based (and very "rational") school system vis-a-vis the 
unverified promises of techno-progressivism. Conversely, teachers from mainland Europe were much more resolute and enthusiastic in their "faith".

Were English teachers inherently more "attuned" to rational choice in their technology-related beliefs than their continental counterparts? It is indeed a possible explanation, one which would align with the established narrative whereby English culture and history are profoundly tied to the development of rationality as a paradigm to make sense of individual and social life - a paradigm dating back to what Green and Shapiro (1994: 18) called the "embryonic rational choice arguments of Hobbes (who assumed that individuals maximise power) and Bentham (who assumed that they maximise pleasure)". However, this explanation is ultimately unsatisfactory. The data suggested that the overall belief system shared by English teachers was far from emotionless. Instead, discursive manoeuvres created an appearance of objectivity and instrumentality, while emotions were pushed in the background and allowed to emerge when contingent factors caused the relaxation of the relentless economic, transactional demands. The emphasis on efficiency and pragmatism provided therefore a degree of legitimation for these teachers, in a manner consistent with established social conventions, but it concealed an underlying ambivalence (Goodwin et al. 2009). This more ambivalent discourse can perhaps be understood better as a discursive "performance" influenced by a desire to reaffirm the "innovator identity" in the turbulent and politically contested world of English education, where educational policies over a period of approximately 20 years created a culture of self-management, brazen pragmatism and relentless accountability. These traits of English educational culture are also noted by Grek and Ozga (2009) in their comparative analysis of European education systems. Drawing on the sociology of Zygmunt Bauman, they describe it as a form of "calculative rationality" (Bauman 1992). Ozga (2009) expands on this point arguing that the English educational landscape is closer to that of the USA than to continental Europe, inasmuch as "ideologies of the market" have informed policies emphasising choice, competition, data-based governance and private sector involvement. The data discussed here seems to confirm Ozga's thesis, but while economic pragmatism provided a "dominant" discursive frame for English teachers' accounts, emotions still offered an alternative way through which they made sense of their behaviour in relation to technology.

On the other hand, continental teachers espoused in less ambivalent terms the "solutionist" rhetoric associated with digital technology, displaying shared beliefs about innovation as an ill-defined collection of technological affordances and potentials leading to an incredibly broad range of societal benefits. This very emotional and personally invested celebration was never based on rational accounts of how networking technologies and social media platforms operate, nor did they reflect an awareness of their economic costs. Rather, they were underpinned by a utopian faith whereby real and imagined properties were arbitrarily (and emotionally) conflated in an endlessly malleable entity (the "Internet"), whose qualities are universal, freely accessible and undisputedly "good". Following again Grek and Ozga (2009) in their sociological analysis, the theme of innovative agency appears here subsumed under the broader narrative of European utopianism. Historically, this narrative recruited education in the emotional and "mythical" process of creating a European "imagined community" (Grek and Ozga 2009, p. 941), and is still reflected in many EU-funded educational interventions such as the Erasmus programme - or the iTEC project under consideration 
in this paper. While this educational narrative places less emphasis on rationalisation and performativity compared to the English case, it seems more susceptible to the allure of technological solutionism.

To bring to an end this discussion, I would like to argue that the dynamics described in this paper highlight a need for a more complex model of teacher agency in relation to technology- one that can adequately account for the entanglement of educational cultures, policies, rationality and emotional dimensions. In such a model, rationality and emotionality should not be considered at face value, that is, inherent traits somehow correlated with psychological qualities that teachers may or may not possess, but as phenomena to be unpacked: competing (and culturally shaped) strategies enacted to make sense of the world (Geertz 1983; Weick 1995). Technology is integral part of these strategies: a constituting and constituted factor at the same time (Feenberg 1991; Pinch and Bijker 1987; Wajcman 2010), and occupying a symbolic, cultural place straddling rationality and emotions. The fact that its inner workings are often "hidden from view" reinforces a cultural trend whereby real and "imagined" technological affordances are conflated in narratives of progress and social or individual empowerment, sometimes in open conflict with the realities of efficiency and accountability, which in turn have their own powerful technological dimensions. There are therefore several "technological discourses" - some more emotional than others - that need to be accounted for and critiqued when examining the topic of technology adoption in formal school settings.

This paper also argues for a reconsideration of the interplay between emotions and rationality in the complex dynamics that shape behaviour - whether or not technology is involved (Kelchtermans 2005; Sutton and Wheatley 2003; Zembylas 2003). As well as shaping agency, emotions are central to the "routine operations of the structures of social interactions" (Barbalet 2001: 3) and are in turn shaped by expectations, cultural values and cognitive predispositions. As Goodwin, Jasper and Polletta reason when discussing the role of emotions in social movements:

Cognitions typically come bundled with emotions, and are meaningful or powerful to people for precisely this reason. Long-lasting moods and affective ties, for their part, may make people more susceptible to certain beliefs and understandings. Rather than viewing emotions and cognitions in zero-sum terms, then, we need to grapple with their interactions and combinations (200: 16).

Concluding, it is important to highlight some of this paper's limitations. In the first place, the selection of informants and interviewees was not guided by the research questions outlined in Section Two, but by contingent factors within the two projects. Although very similar, these projects still had a number of specific objectives that informed the data collection activities. Future studies should therefore strive to select participants on the basis of more rigorous theoretical sampling, in which data collection is iterative and informed by the emerging interpretative picture (Glaser and Strauss 1967; Patton 1990). The sample was also relatively small and the interpretation very reliant upon discursive accounts. A more comprehensive qualitative analysis of technology-related agency should therefore include more naturally occurring and observational data, possibly collected over a sustained period. Also largely absent from the analysis is an account of the actual technology and its influence on pedagogic 
practices and learning outcomes. Although, it should be emphasised, it was not the aim of this paper to provide such an account. Notwithstanding these limitations, this paper still makes an important contribution by disputing the linear and simplistic appropriation of rational choice in educational research, whereby individual behaviour is examined from the perspective of individualist psychology and micro-economic theory without considering models of culturally informed agency beyond self-interest and calculation. A final point about the broader relevance of this contribution. In the global north, the adoption of innovations in formal education is probably less pressing an issue than it used be a decade ago. However, it remains a topic of great concern in the developing world, where many countries have recently implemented strong policy initiatives and programmes for educational technology with high-level governmental support (International Telecommunication Union 2014). The suggestion made in this paper is that research and interventions in these challenging realities have a duty to appreciate the interweaving of cultures, beliefs and emotions which not only lies at the heart of technology adoption, but of educational practice in general.

Acknowledgments The ITL project was sponsored by Microsoft Partners in Learning. The iTEC project was funded by the European Commission (Project reference: 257566).

The original idea behind this paper dates back to the time I spent at the Institute of Education in London from 2010 to 2012. I would like to thank Neil Selwyn (now at Monash University, Australia) and John Potter for their role in shaping my current thinking around educational technology.

Open Access This article is distributed under the terms of the Creative Commons Attribution 4.0 International License (http://creativecommons.org/licenses/by/4.0/), which permits unrestricted use, distribution, and reproduction in any medium, provided you give appropriate credit to the original author(s) and the source, provide a link to the Creative Commons license, and indicate if changes were made.

\section{References}

Barbalet, J. M. (2001). Emotion, social theory, and social structure: A macrosociological approach. Cambridge: Cambridge University Press.

Bauman, Z. (1992). Intimations of postmodernity. London: Routledge.

Calderhead, J. (1996). Teachers: Beliefs and knowledge. In D. Berliner \& R. Calfee (Eds.), Handbook of educational psychology (pp. 709-725). New York: Routledge.

Cuban, L., Kirkpatrick, H., \& Peck, C. (2001). High access and low use of technologies in high school classrooms: explaining an apparent paradox. American Educational Research Journal, 38, 813-834.

Davis, F. D. (1989). Perceived usefulness, perceived ease of use, and user acceptance of information technology. MIS Quarterly, 13, 319-339.

Davis, F. D., Bagozzi, R. P., \& Warshaw, P. R. (1989). User acceptance of computer technology: a comparison of two theoretical models. Management Science, 35, 982-1002.

Du Gay, P., Hall, S., Janes, L., Madsen, A. K., Mackay, H., \& Negus, K. (2013). Doing cultural studies: The story of the Sony Walkman. London: Sage.

Ertmer, P. A. (2005). Teacher pedagogical beliefs: the final frontier in our quest for technology integration? Educational Technology Research and Development, 53(4), 25-39.

Ertmer, P. A., \& Ottenbreit-Leftwich, A. T. (2010). Teacher technology change: how knowledge, confidence, beliefs, and culture intersect. Journal of Research on Technology in Education, 42(3), 255-284.

Ertmer, P. A., Gopalakrishnan, S., \& Ross, E. M. (2001). Technology-using teachers: Comparing perceptions of exemplary technology use to best practice. Journal of Research on Technology in Education, 33(5). Available online at http://www.iste.org/jrte/33/5/ertmer.html.

Fang, Z. (1996). A review of research on teacher beliefs and practices. Educational Research, 38(1), 47-65.

Feenberg, A. (1991). Critical theory of technology. Oxford: Oxford University Press. 
Fishbein, M., \& Ajzen, I. (1975). Belief, attitude, intention and behavior: An introduction to theory and research. Reading: Addison-Wesley.

Geertz, C. (1983). Local knowledge: Further essays in interpretive anthropology (Vol. 5110). Jackson: Basic Books.

Glaser, B. G., \& Strauss, A. L. (1967). The discovery of grounded theory; Strategies for qualitative research. Chicago: Aldine.

Goodwin, J., Jasper, J. M., \& Polletta, F. (Eds.). (2009). Passionate politics: Emotions and social movements. Chicago: University of Chicago Press.

Green, D. P., Shapiro, I., \& Shapiro, I. (1994). Pathologies of rational choice theory: A critique of applications in political science. New Haven: Yale University Press.

Grek, S., \& Ozga, J. (2009). Governing education through data: Scotland, England and the European education policy space. British Educational Research Journal, 36(6), 937-952.

Guba, E. G. (1981). Criteria for assessing the trustworthiness of naturalistic inquiries. Educational Communication \& Technology Journal, 29(2), 75-91.

Hall, S. (Ed.). (1997). Representation: Cultural representations and signifying practices (Vol. 2). London: Sage.

Hartley, D. (2003). The instrumentalisation of the expressive in education. British Journal of Educational Studies, 51(1), 6-19.

Hofstede, G., Hofstede, G. J., \& Minkov, M. (1997). Cultures and organizations. New York: McGraw Hill.

Howard, S. K., \& Gigliotti, A. (2015). Having a go: looking at teachers' experience of risk-taking in technology integration. Education and Information Technologies, 1-16. Published online: 6 March 2015. doi: 10.1007/s10639-015-9386-4.

International Telecommunication Union (ITU) (2014). Partnership on measuring ICT for development. Final WSIS Targets Review. Achie0076ements, Challenges and the Way Forward. Geneva: ITU. Available online: www.itu.int.

Jimoyiannisa, A., \& Komisb, V. (2007). Examining teachers' beliefs about ICT in education: implications of a teacher preparation programme. Teacher Development, 11(2), 149-173.

Kelchtermans, G. (2005). Teachers' emotions in educational reforms: self-understanding, vulnerable commitment and micropolitical literacy. Teaching and Teacher Education, 21(8), 995-1006.

Kim, C., Kim, M. K., Lee, C., Spector, J. M., \& DeMeester, K. (2013). Teacher beliefs and technology integration. Teaching and Teacher Education, 29, 76-85.

Langworthy, M., Shear, L., \& Means, B. (2010). The third lever. In Inspired by Technology, Driven by Pedagogy A Systemic Approach to Technology-Based School Innovations, OECD Centre for Educational Research and Innovation, pp. 105-124. Available online: http://bit.ly/1eCwEDd.

Legris, P., Ingham, J., \& Collerette, P. (2003). Why do people use information technology? A critical review of the technology acceptance model. Information \& Management, 40(3), 191-204.

Lewin, C., \& McNicol, S. (2014). Creating the future classroom: evidence from the iTEC project. Published by Manchester Metropolitan University. Available online: http://bit.ly/1CWxuRb.

Mansfield, C. F., \& Volet, S. E. (2010). Developing beliefs about classroom motivation: journeys of preservice teachers. Teaching and Teacher Education, 26(7), 1404-1415.

Nistor, N., Lerche, T., Weinberger, A., Ceobanu, C., \& Heymann, O. (2014). Towards the integration of culture into the unified theory of acceptance and use of technology. British Journal of Educational Technology, 45(1), 36-55.

Ozga, J. (2009). Governing education through data in England: from regulation to self-evaluation. Journal of Education Policy, 24(2), 149-162.

Patton, M. Q. (1990). Qualitative evaluation and research methods (2nd ed.). Newbury Park, California: Sage.

Pinch, T. J., \& Bijker, W. E. (1987). The Social Construction of Facts and Artifacts: Or How the Sociology of Science and the Sociology of Technology Might Benefit Each Other. The Social Construction of Technological Systems: New Directions in the Sociology and History of Technology pp. 17-54.

Rogers, E. M. (2003). Diffusion of innovations (5th ed.). London: Simon and Schuster.

Roehrig, G. H., Kruse, R. A., \& Kern, A. (2007). Teacher and school characteristics and their influence on curriculum implementation. Journal of Research in Science Teaching, 44, 883-907.

Scherer, R., Siddiq, F., \& Teo, T. (2015). Becoming more specific: measuring and modeling teachers' perceived usefulness of ICT in the context of teaching and learning. Computers \& Education, 88, 202214.

Selwym, N., \& Grant, L. (2009). Researching the realities of social software use-an introduction. Learning, Media and Technology, 2(39), 79-86.

Selwyn, N. (2010). Looking beyond learning: notes towards the critical study of educational technology. Journal of Computer Assisted Learning, 26(1), 65-73. 
Shear, L., \& Moorthy, S. (2010). Innovation around the world: ICT-supported educational innovation in four countries. Global Learn, 1, 618-623.

Signorini, P., Wiesemes, R., \& Murphy, R. (2009). Developing alternative frameworks for exploring intercultural learning: a critique of Hofstede's cultural difference model. Teaching in Higher Education, 14(3), 253-264.

Sokolowski, R. (2000). Introduction to phenomenology. Cambridge: Cambridge University Press.

Somekh, B. (2008). Factors affecting teachers' pedagogical adoption of iCT. In J. Voogt \& G. Knezek (Eds.), International handbook of information technology in primary and secondary education (pp. 449-460). New York: Springer.

Straub, E. T. (2009). Understanding technology adoption: theory and future directions for informal learning. Review of Educational Research, 79(2), 625-649.

Straub, D., Keil, M., \& Brenner, W. (1997). Testing the technology acceptance model across cultures: a three country study. Information \& Management, 33(1), 1-11.

Sutton, R. E., \& Wheatley, K. F. (2003). Teachers' emotions and teaching: a review of the literature and directions for future research. Educational Psychology Review, 15(4), 327-358.

Teo, T. (2009). Modelling technology acceptance in education: a study of pre-service teachers. Computers \& Education, 52(2), 302-312.

Venkatesh, V., Morris, M. G., Davis, G. B., \& Davis, F. D. (2003). User acceptance of information technology: toward a unified view. MIS Quarterly, 27(3), 425-478.

Wajcman, J. (2010). Feminist theories of technology. Cambridge Journal of Economics, 34(1), 143-152.

Weick, K. (1995). Sensemaking in organizations (Vol. 3). London: Sage.

Zembylas, M. (2003). Emotions and teacher identity: a poststructural perspective. Teachers and Teaching: Theory and Practice, 9(3), 213-238.

Zhao, Y., \& Frank, K. A. (2003). Factors affecting technology uses in schools: an ecological perspective. American Educational Research Journal, 40(4), 807-840. 